\title{
IS LAPAROSCOPY A SAFE AND A COST EFFECTIVE ALTERNATIVE IN THE SURGICAL MANAGEMENT OF IDIOPATHIC THROMBOCYTOPENIC PURPURA (ITP)?
}

\author{
K.B. Galketiya ${ }^{1}$, V. Pinto ${ }^{2}$, D. Dissanayake³, G.W.G.D.D. Galahawela ${ }^{2}$ \\ ${ }^{1}$ Department of Surgery, Faculty of Medicine, University of Peradeniya, Sri Lanka \\ ${ }^{2}$ Department of Anaesthesiology and Critical Care, Faculty of Medicine, University of Peradeniya, \\ Sri Lanka \\ ${ }^{3}$ Department of Pathology, Faculty of Medicine, University of Peradeniya, Sri Lanka \\ Corresponding Author: Prof K.B. Galketiya, Email: kbgalketiya@yahoo.com
}

Doi: $\underline{\text { http://dx.doi.org/10.4038/sljm.v25i2.20 }}$

\begin{abstract}
Background: Splenectomy is indicated for idiopathic thrombocytopenic purpura (ITP) when medical management fails. Laparoscopy reduces the morbidity of open splenectomy.

Objectives: To evaluate the technique, advantages and outcomes of laparoscopic splenectomy for ITP.

Methods: A retrospective analysis of laparoscopic splenectomy performed at Teaching Hospital Peradeniya from 2008 to 2014 was carried out.

Results: Thirty-two patients, with platelet counts less than $100 \times 10^{9} /$ l, underwent the procedure. The duration of surgery ranged from 60 to 270 minutes with minimum blood loss and no conversions to open surgery. All were discharged by the third or fourth day of surgery with the platelet counts rising above $150 \times 10^{9} / \mathrm{l}$.

Conclusions: Laparoscopy is a safe and effective technique for splenectomy. It is associated with lower morbidity and early recovery.
\end{abstract}

Keywords: ITP, Laparoscopy, Splenectomy

\section{Introduction}

Idiopathic thrombocytopenic purpura (ITP) is initially managed medically. The target is to maintain a platelet count above $60 \times 10^{9}$ \% l. When it is difficult to achieve adequate levels or if there is a dependency on steroids a splenectomy is indicated.

Splenectomy by open surgical access involves a midline or left sub costal incision which can cause a substantial morbidity. The surgical incision may bleed excessively. Other complications of laparotomy include post-operative pain which can affect mobilization and breathing, wound infection and later complications such as incisional hernia ${ }^{1}$. In a young person a scar is of cosmetic concern.

These complications can be reduced by laparoscopic approach which bears a smaller incision ${ }^{2,3,4}$. In addition, it provides a clear vision by magnification and zooming which enables a better surgical dissection ${ }^{5}$. Exposure of the peritoneal cavity to the exterior will be less and there will be minimal tissue handling, carrying a lesser risk of post-operative infections. Early mobilization, feeding and early discharge from hospital are other potential advantages. There will be a learning curve with challenges of tissue dissection, mobilization, 
haemostasis and retrieval of the spleen, which may increase the operative time ${ }^{3,6}$. The aim of this study was to evaluate the technique, advantages and outcomes of laparoscopic splenectomy for ITP.

\section{Materials and Methods}

A retrospective analysis of laparoscopic splenectomy performed at Teaching Hospital Peradeniya (THP) from 2008 to 2014 was carried out. All the patients with ITP, referred by the consultant haematologist for splenectomy were recruited. Informed consent was obtained prior to surgery. Patients were immunized with pneumococcal, meningococcal and Hib vaccines as recommended. Patients with platelet counts lower than $50 \times 10 \%$ l were treated with immunoglobulin.

Surgery was performed under general anaesthesia. A naso-gastric tube was placed. The position used was right lateral decubitus with a 45 degrees inclination and a head up tilt of 30 degrees. A pneumoperitoneum was established with veress needle with an insufflation pressure of $14 \mathrm{mmHg}$. Intravenous hydrocortisone was given as all patients were on long term prednisolone. A $10 \mathrm{~mm}$ camera port was inserted $5 \mathrm{~cm}$ from the left costal margin. Additional ports for retraction and two hand dissection were inserted (Table 01).

The respiratory and cardiovascular parameters were recorded. Ventilatory adjustments were made to clear the extra $\mathrm{CO}_{2}$ load. Gastrocolic, gastrosplenic, splenocoloic, splenophrenic ligaments were mobilized. Mobilization using an ultrasonic dissector and bipolar diathermy allows a quick and bloodless procedure. With entry in to the lesser sac at an early stage of the surgery, the splenic artery was defined and clipped. The splenic hilum was dissected exposing the splenic artery and vein once the spleen was completely mobilized. The vessels were controlled by clips and bipolar diathermy, and divided with the ultrasonic dissector. Once the spleen was free a careful inspection was done for accessory spleens. The spleen was placed in a pouch made by fashioning a urine bag. The pouch with the contained spleen was retrieved via a mini incision of about $5 \mathrm{~cm}$.

The following collected data were reviewed.

1. Patient details

2. Pre-operative medication for ITP

3. Pre-operative platelet count

4. Respiratory and cardio-vascular parameters

5. Blood loss

6. Transfusion requirement

7. Duration of surgery

8. Conversions to open surgery

9. Post-operative platelet count

10. Post-operative recovery

\section{Results}

A total number 32 patients, 24 females and 8 males, underwent the procedure. The age ranged from 10 years to 72 years.

Table 1: Additional ports inserted for retraction and two and dissections

\begin{tabular}{|c|c|c|}
\hline Port site & Port size & Port function \\
\hline Epigastric & $5 \mathrm{~mm}$ & Retraction of stomach/spleen \\
\hline $\begin{array}{l}\text { Midway of xiphoid and } \\
\text { umbilicus }\end{array}$ & $5 \mathrm{~mm}$ & Left hand working \\
\hline Mid clavicular, umbilical level & $10 \mathrm{~mm}$ & Left hand working \\
\hline Anterior axillary & $5 \mathrm{~mm}$ & Retraction of colon/ pancreas \\
\hline
\end{tabular}


Table 2: Pre-operative medications used

\begin{tabular}{ll}
\hline Medication & Number \\
\hline Steroids & 32 \\
Azathioprine & 4 \\
Immunoglobulin & 3 \\
\hline
\end{tabular}

Pre-operative medications used on the study cohort are given in Table 02.

All patients had platelet counts less than 100 x $10 \%$ l. Six patients who had counts below $50 \times 10^{9} / 1$ were treated with immunoglobulin prior to surgery.

In two out of them the platelet counts didn't improve and the operation was conducted with counts of 8 and $10 \times 10^{9} /$.

The duration of surgery ranged from 60 to 270 minutes with no conversions. The mean duration was 146.5 min with a SD of 39.4 min and the median duration was 150 mins. The mean blood loss during surgery was $53.4 \mathrm{ml}$ (SD $19.9 \mathrm{ml}$ ) and the median blood loss was $50 \mathrm{ml}$. None required transfusion of blood. Two patients operated with platelet counts less than $50 \times 10^{9} / \mathrm{l}$ were transfused platelets just after ligation of the splenic artery. The patients' respiratory and cardiovascular parameters were stable during the procedure.

All the patients were encouraged to sit up, and oral sips were started the same day night. Pain relief was achieved by oral analgesics. By next day, all were mobilized out of bed and oral feeding was commenced. The steroids were tailed off. The patients were discharged by the third or fourth post operative day on a prophylactic dose of oral penicillin.

The platelet counts were above $150 \times 10^{9}$ / l in all during follow up. The rise was noted on post-operative day one.

One patient presented one week later with fever. Clinical examination was unremarkable and she was started on oral co-amoxyclav. She continued to have persistent fever and left hypochondriac pain. Ultrasound scan revealed a left subdiagphramatic collection which was drained under ultrasound guidance.

\section{Discussion}

Performing splenectomy by laparoscopy reduces the morbidity of open access ${ }^{1-4}$. The pain is less due to the smaller incision. Less pain allows early mobilization, feeding and early discharge from hospital, which is evident in our series, as in published international data ${ }^{1-3}$. The majority were young and the cosmetic advantage of a smaller incision was an added benefit. The chances of wound infection, early or late wound dehiscence are less, especially considering that they were on long term steroids. We did not have any wound related complications.

The risk for post-operative infections may be less with minimal access as there is less tissue handling and less exposure to the exterior. Out of 32 we had one patient with a left sub-diagphramatic abscess. This was successfully managed with ultra-sound guided aspiration and intra-venous antibiotics.

With laparoscopy the visibility of internal anatomy is clear due to magnification and zooming effect of the camera. However with a complex dissection the surgeon has to experience a steep learning curve. This is evident by the long operative time at the beginning of the series. During the latter part of the study it had significantly shortened, which is shown in published data as well. In spite of the bleeding risk, mobilizations were relatively bloodless by the use of energy sources; bipolar diathermy and ultrasonic dissector ${ }^{6}$. The splenic artery and vein may be controlled by vascular staplers which is expensive. We obtained vascular control with clips and energy sources. The blood losses were insignificant and none required transfusion of blood.

During surgery the created pneumoperitoneum causes diaphragmatic 
splinting, intra abdominal venous compression and increased $\mathrm{CO}_{2}$ load. The insufflations pressure of $14 \mathrm{mmHg}$ was well tolerated with respiratory and cardiovascular stability.

The clear vision allows recognition of accessory spleens which according to literature is superior to computerized tomography ${ }^{5}$.

Even with a steep learning curve there were no conversions to open surgery in our series. Removal of the spleen may be done with retrieval in to an endobag, which is costly. We used a fashioned urine bag for this purpose.

The post-operative platelet counts were increased in all patients and prednisolone was tailed off indicating an effective outcome.

\section{Conclusions}

Laparoscopy is a safe and effective technique for splenectomy. It is associated with lower morbidity and early recovery.

Conflicts of Interest: None

\section{References}

1. Winslow E, Brunt L. Perioperative outcomes of laparoscopic versus open splenectomy: A meta-analysis with an emphasis on complications. Surgery. 2003;134(4):647-653.Doi: 10.1016/S0039-6060(03)00312-X

2. Ray U, Gupta S, Chatterjee S, SenGupta T, Gupta N. Laparoscopic versus open splenectomy in the treatment of idiopathic thrombocytopenic purpura: an Indian experience. Journal of the Indian Medical Association. 2012;110(12):889893.

3. Nyilas A, Paszt A, Simonka Z, Abrahám S, Pál T, Lázár G. Comparison of laparoscopic and open splenectomy.
Magyar sebészet. 2013;66(1):14-20. Doi: 10.1556/MaSeb.66.2013.1.2

4. Ferndale L, Naidoo M, Bhaila S, Thomson S, Bassa F. Laparoscopic splenectomy for immune thrombocytopenic purpura. South African journal of surgery. SuidAfrikaanse tydskrif vir chirurgie. 2013;51(2):54. Doi: 10.7196/sajs.1325

5. Koshenkov V, Pahuja A, Németh Z, Abkin A, Carter M. Identification of Accessory Spleens During Laparoscopic Splenectomy is Superior to Preoperative Computed Tomography for Detection of Accessory Spleens. Journal of the Society of Laparoendoscopic Surgeons. 2012;16(3):387-391. Doi 10.4293/108680812X13427982377102

6. Fujioka S, Yoshida K, Okamoto T, Yanaga K. Stapleless Laparoscopic Splenectomy Using Harmonic Scalpel by 2-Step Sealing. International Surgery. $\quad$ 2013;98(4):385-387. Doi: 10.9738/INTSURG-D-13-00035.1 